\section{Dr. Olech, et al reply}

\section{To the Editor:}

We appreciate the interest in our article and the comments in the above letters. Like Dr. Rothschild, we also were surprised by the frequency of erosions in the nonrheumatoid controls, even though one of our authors, Dr. John Crues, who is a musculoskeletal radiologist, finds these frequently in orthopedic patients being imaged for nonarthritis reasons, e.g., occult fractures. We agree with Dr. Rothschild that it will be intriguing to learn of the natural history of these lesions.

Interestingly, the same month our report was published, another article in Arthritis and Rheumatism compared the periarticular bone structure of patients with rheumatoid arthritis (RA) to that of healthy individuals by high-resolution computed tomography $(\mathrm{CT})^{1}$. Destruction of the cortical bone lamella marking bone erosions in the unilateral second, third, and fourth digits and the proximal wrist was identified in $37 \%$ of 30 healthy individuals. Similar to our findings, the distribution of the bone lesions in these healthy individuals was analogous to the patients with RA. Changes of cortical bone correlated with age in the healthy subjects, correspondingly to our control group. McGonagle, et al showed that microanatomic erosion-like changes in the periligamentous locations prone to microdamage can be observed in the joints of healthy individuals ${ }^{2}$. These were present in the same topographic distribution as in patients with RA, implying relation to a mechanical stress.

As Dr. Barbieri, et al pointed out, based on their experience, erosionlike lesions in healthy individuals may be bone cysts. Per Dr. Rothschild's suggestion, some of the magnetic resonance imaging (MRI) lesions may also represent an underlying disease, such as sickle cell anemia. However, an underlying disease would not explain such a high prevalence of these lesions. Therefore, we hypothesize, based on our findings and those of others, that rheumatoid erosions might be a disorder of quantity more than a unique event. Indeed, osteoclasts are known to be involved in bone homeostasis in healthy individuals; perhaps when using more sensitive instruments, this finding might have been expected.

While CT images or plain radiographs may help to clarify the underlying disease or depict bone cysts, it should be emphasized that MRI is a technique that looks at dynamic soft-tissue processes closely associated with pathophysiology, while the other 2 techniques evaluate calcium density - a passive bystander of active pathophysiology, and a reflection of cumulative processes that might take longer to appear.
We have come to the same conclusion as Dr. Barbieri, et al that caution should be used in the interpretation of erosions on MRI. We also agree that CT more accurately displays mineralized bone and sharply marginated regions with calcium loss, while MR signal changes may sometimes represent lesions of low activity (either posttraumatic or low-grade inflammatory). MRI, however, can detect osteitis (marrow edema), which is the more aggressive lesion with a poorer prognosis if left incompletely treat$\mathrm{ed}^{3,4}$. Therefore, we strongly believe that MRI is a superior technique for imaging patients with RA.

EWA OLECH, MD, Assistant Member, Oklahoma Medical Research Foundation, 825 NE 13th Street, Oklahoma City, Oklahoma 73104, USA; JOAN MERRILL, MD, Member, Oklahoma Medical Research Foundation; JOHN CRUES III, MD, Radnet Management, Los Angeles, CA, USA; DAVID YOCUM, MD, Clinical Professor of Medicine, Stanford University, Palo Alto, CA, USA. Address correspondence to Dr. Olech; E-mail: ewa-olech@omrf.org

\section{REFERENCES}

1. Stach CM, Bäuerle M, Englbrecht M, Kronke G, Engelke K, Manger B, et al. Periarticular bone structure in rheumatoid arthritis patients and healthy individuals assessed by high-resolution computed tomography. Arthritis Rheum 2010;62:330-9.

2. McGonagle D, Tan AL, Møller Døhn U, Ostergaard M, Benjamin M. Microanatomic studies to define predictive factors for the topography of periarticular erosion formation in inflammatory arthritis. Arthritis Rheum 2009;60:1042-51.

3. Haavardsholm EA, Bøyesen P, Østergaard M, Schildvold A, Kvien TK. Magnetic resonance imaging findings in 84 patients with early rheumatoid arthritis: bone marrow oedema predicts erosive progression. Ann Rheum Dis 2008;67:794-800.

4. Hetland ML, Ejbjerg B, Hørslev-Petersen K, Jacobsen S, Vestergaard A, Jurik AG, et al; CIMESTRA study group. MRI bone oedema is the strongest predictor of subsequent radiographic progression in early rheumatoid arthritis. Results from a 2-year randomised controlled trial (CIMESTRA). Ann Rheum Dis 2009;68:384-90.

J Rheumatol 2010;37:9; doi:10.3899/jrheum.100387 